\title{
Lipid Extraction of Tissues with a Low-Toxicity Solvent
}

\author{
Atsushi Hara ANd Norman S. Radin \\ Mental Health Research Institute and Department of Biological Chemistry, \\ University of Michigan. Ann Arbor, Michigan 48109
}

Received February 8, 1978

\begin{abstract}
An improved method for extracting the lipids from tissues consists of the use of hexane:isopropanol, followed by a wash of the extract with aqueous sodium sulfate to remove nonlipid contaminants. This method has a number of advantages over the common usage of chloroform:methanol. The solvents are somewhat less toxic, interference in processing by proteolipid protein contamination is avoided, the two phases separate rapidly during the washing step, the solvent density is low enough to permit centrifugation of the homogenate as an alternative to filtration, the solvents are cheaper, and the washed extract can be applied to a chromatographic column with continuous monitoring of the elution in the far ultraviolet region. The new extraction method is inefficient for the extraction of gangliosides.
\end{abstract}

Biochemists wishing to extract lipids from tissues have in the past paid rather little attention to questions of danger to their health or to the health of people living downstream from their sewage treatment plants. Recent findings from public health studies and animal experiments have implicated a wide variety of organic solvents in the production of tumors, through exposure in the work place or in drinking water. It therefore seems appropriate to review lipid extraction techniques as a potential health hazard. While many solvents have been recommended [for reviews see Refs. (1-3)], the most popular is the chloroform:methanol $(\mathrm{CM})^{1}$ system of Folch et al. (4) and its various modifications. Chloroform can produce tumors in animals (5) and methanol is well known for its damage to the visual system.

A choice of solvents for lipid extraction should be made on the basis of several additional factors: volatility (for ready removal later), freedom from toxic or reactive impurities (to avoid reaction with the lipids), ability to form a two-phase system with water (to remove nonlipids), extraction power for undesired components (proteolipid proteins, small molecules), price, range of extraction power for the different lipid classes, and ultraviolet transparency for subsequent column chromatography and monitor-

${ }^{1}$ Abbreviations used: HIP, hexane:isopropanol, usually in the ratio 3:2. CM, chloroform: methanol, usually in the ratio $2: 1$. 
ing in the low wavelength region. Chloroform rates low with respect to impurities ( $\mathrm{HCl}$ and phosgene), price, and transparency. After examining the various available solvents, we turned to hexane:isopropanol (HIP). Hexane in high concentrations is a known neurotoxin, apparently through metabolism to the 2,5-diketo compound (6), but it seems to be relatively nontoxic in laboratory usage and probably is not a hazard after sewage processing. Until recent years commercial hexane was contaminated with sulfur and aromatic compounds, which tend to polymerize to nonvolatile materials, but contemporary hexane is much purer. Our trials with HIP indicate that it satisfies many of the needs of the lipid chemist and shows significant advantages over other systems.

\section{METHOD AND EVALUATION}

Materials. Hexane ("nonspectro") was the product of Burdick \& Jackson Laboratories, Muskegon, Michigan. Some work was done with "hexanes," J. T. Baker Analyzed Reagent grade, distilled before use. Isopropanol was the reagent grade product, also redistilled. Radioactive ganglioside $G_{M 1}$, made by the galactose oxidase/borohydride method (7), and crude $\mathrm{G}_{\mathrm{M} 1}$ were gifts of Dr. K. Suzuki. Radioactive glucocerebroside and sphingomyelin were prepared here, and labeled cerebroside sulfate was a gift from Dr. Y. Kishimoto.

Thin-layer chromatography was done with commercially coated silica gel plates (EM Laboratories), using chloroform:methanol:water $(65: 25: 4)$ or hexane:diethyl ether:acetic acid (80:20:1). The plates were sprayed with iodine in methanol, ninhydrin, phospholipid detecting spray (8), or a cupric:phosphoric acid charring spray (9).

Column chromatography was carried out with Silica Gel 60, 230/400 mesh (EM Laboratories).

Lipid extraction technique. Rat or mouse brain was used for all the tests. To $1 \mathrm{~g}$ of brain was added $18 \mathrm{ml}$ of hexane:isopropanol (3:2), the mixture was homogenized with a Polytron (Brinkmann Instruments) for $30 \mathrm{~s}$, and the suspension was filtered through a sintered glass Buchner funnel (medium porosity) fitted with a ball joint for use with pressure (10). The homogenizer, funnel, and residue were washed three times with $2-\mathrm{ml}$ portions of HIP, by resuspending the residuc cach time and letting the solvent soak for 2 min before applying air pressure.

If desired, nonlipids in the extract could be removed by mixing the pooled filtrates for at least $1 \mathrm{~min}$ with $12 \mathrm{ml}$ of aqueous sodium sulfate (prepared from $1 \mathrm{~g}$ of the anhydrous salt and $15 \mathrm{ml}$ of water). The two layers that formed were each about $18 \mathrm{ml}$ in volume. The lipids were in the upper, hexane-rich layer. No precipitate was visible at the interface.

Caution. Hexane is relatively flammable and ventilation may be needed near the homogenizer. 
Evaluation of the HIP extraction method. Most of the evaluation was done by comparing similar portions of brain that were extracted and washed according to a slight modification of the procedure of Folch et al. (4). One gram of chopped, blended brain was homogenized as above with $18 \mathrm{ml}$ of chloroform:methanol (2:1) and the residue was rinsed as above wtih $3 \times 2 \mathrm{ml}$ of the same solvent. Washing of the pooled filtrates was done with $4.8 \mathrm{ml}$ of $0.88 \% \mathrm{KCl}$.

When a CM filtrate was evaporated to dryness and dissolved in HIP or $\mathrm{CM}$, much denatured proteolipid protein and other insoluble material could be seen. In the case of HIP extracts, the solutions were clear, indicating the absence of proteolipid protein and a reduced amount of nonlipid contamination. This interpretation was confirmed by analyzing the washed extracts for protein by the method of Lowry et al. (11), modified for proteolipids (12). The CM extract contained $3.2 \mathrm{mg}$ of protein $/ \mathrm{g}$ of brain, while none could be detected in the HIP extract.

An attempt to extract the proteolipid protein from the residue remaining from HIP extraction, by treatment with chloroform-methanol-water 10:10:1, yielded only $0.9 \mathrm{mg}$ of protein $(0.5 \mathrm{mg}$ in the case of CM residue). Evidently the HIP treatment denatures it, or fails to convert the myelin protein to a $\mathrm{CM}$-soluble form. The proteinaceous residue from brain dries to a dark, keratin-like material after CM extraction, but the residue from HIP extraction is light in color and fluffy.

The HIP extracts apparently contained less of the other nonlipid tissue materials. In an experiment with $1 \mathrm{~g}$ of hrain, the first CM extract contained $95.2 \mathrm{mg}$ of dry solids while the HIP extract contained $79.9 \mathrm{mg}$ (15.3 $\mathrm{mg}$ less). Washing the extracts once with $\mathrm{KCl}$ or $\mathrm{Na}_{2} \mathrm{SO}_{4}$ removed $15.7 \mathrm{mg}$ from $\mathrm{CM}$ and $7.0 \mathrm{mg}$ from HIP. The HIP extract then contained 6.6 $\mathrm{mg}$ less material than the $\mathrm{CM}$ extract; only about $3.2 \mathrm{mg}$ of this difference could be accounted for by the absence of proteolipid protein.

Examination of all four extracts, washed and unwashed, by thin-layer chromatography, using 0.1 and $0.3-\mathrm{mg}$ of lipids, revealed no differences in the major bands but distinct differences were visible in the material at the origin and just above. Ninhydrin revealed a distinct band at the origin from CM extracts and a lesser band just above; the unwashed HIP extract also showed these bands, but only faintly. Iodine showed the low bands even more clearly and a trace was now visible even in the washed HIP lipids. Evidently a single wash of the CM lipids was insufficient to remove an appreciable amount of nonlipid material.

The lipids extracted by the two solvent systems were compared after column chromatography. Extraction was carried out as above with $2 \mathrm{~g}$ of rat brain and the unwashed extracts were concentrated to dryness with a stream of nitrogen, followed by high vacuum desiccation. Both preparations were treated with $18 \mathrm{ml}$ of $70 \mathrm{mM} \mathrm{NaOH}$ in $\mathrm{CM}$ (13) for $60 \mathrm{~min}$ and soluble nonlipids were removed by partitioning with $4.5 \mathrm{ml}$ of $0.28 \mathrm{M}$ 
aqueous acetic acid. The lower layer was washed twice with $10 \mathrm{ml}$ of $0.88 \%$ $\mathrm{KCl}$ :methanol (1:1), precipitated protein in the CM lipids was removed by filtration, and the lipid solution was evaporated to dryness. The lipids were suspended in hexane and applied to a column containing $6 \mathrm{~g}$ of silica gel.

Elution with $60 \mathrm{ml}$ of hexane yielded the hydrocarbon fraction, 150 $\mathrm{ml}$ of hexane-toluene $1: 1$ yielded the fatty acid methyl esters $(72.7 \mathrm{mg}$ from HIP, $74.3 \mathrm{mg}$ from CM), $150 \mathrm{ml}$ of HIP 95:5 yielded free fatty acids and cholesterol (43.9 and $44.4 \mathrm{mg}$, respectively), and $150 \mathrm{ml}$ of hexaneisopropanol-water 60:80:14 yielded the polar alkali-stable lipids (60.8 and $60.1 \mathrm{mg}$, respectively). The total yield of lipids from the column was $177.3 \mathrm{mg}$ from the HIP extract and $178.7 \mathrm{mg}$ from the CM extract.

This study showed that both solvents extracted very similar amounts of most of the lipids, but that the methyl ester yield was slightly higher with CM. This difference was observed in several experiments. Part of the difference must arise from the failure of HIP to extract proteolipid protein, which contains fatty acids that are rapidly liberated by alkaline methanolysis (14).

Thin-layer chromatography of the lipids obtained by column fractionation showed no difference between the two extracts. Gas chromatography of the methyl esters with programmed temperature and poly(diethyleneglycol succinate) columns showed there was no difference in fatty acid distribution. The content in weight percentage of each major fatty acid was $20 \% 16: 0,20 \% 18: 0,26.5 \% 18: 1,3 \% 20: 1,10 \% 20: 4,3 \% 22: 4$, and $14 \% 22: 6$.

The fatty acids missing from the HIP extract were sought in the insoluble protein/nucleic acid residue. This residue was dried, then heated overnight at $100^{\circ} \mathrm{C}$ in a sealed tube with $8 \mathrm{ml}$ of $4 \mathrm{M}$ methanolic $\mathrm{HCl}$. The fatty acid methyl esters were extracted with $3 \times 16 \mathrm{ml}$ of hexane, the esters were purified by chromatography on silica gel as above, and the weights were determined by gas chromatography as above, using an internal standard, tricosanoic acid. The HIP residue contained $3.4 \mathrm{mg}$ and the $\mathrm{CM}$ residue contained $1.5 \mathrm{mg}$ (a difference of $1.84 \mathrm{mg}$ ). While part of this difference in contents is due to proteolipid protein fatty acids, as noted above, another part must come from a difference in ganglioside extraction as noted below.

The distribution of fatty acids in the proteinaceous residue differed appreciably from that seen in whole brain and the two residues showed some differences from each other. The HIP residue contained $22 \% 16: 0$, $39 \% 18: 0,13 \% 18: 1,2 \% 20: 0,12 \% 20: 4$, and 5\% 22:6. The CM residue contained $29 \% 16: 0,31 \% 18: 0,13 \% 18: 1,17 \% 20: 4$, and 2\% 22:6. Probably some of these fatty acids were derived from polyphosphoinositides, which require $\mathrm{HCl}$ or $\mathrm{CaCl}_{2}$ in $\mathrm{CM}$ for extraction.

Gangliosides are extracted readily by $\mathrm{CM}$, preferably in the ratio $1: 2$, 
and are largely removed from the extract by partitioning with aqueous salts. Ganglioside behavior in HIP was tested by evaporating to dryness in the homogenizing tube $0.43 \mathrm{mg}$ of $\left[{ }^{3} \mathrm{H}\right.$ ]ganglioside $\mathrm{G}_{\mathrm{M}_{1}}$ [GalGalNAc(NAN)GalGlc ceramide]. To this was added $0.5 \mathrm{~g}$ of chopped brain and the lipids were extracted with HIP or CM. In the case of HIP, only $44 \%$ of the tritium was found in the filtrate; in the case of $\mathrm{CM}, 95 \%$ was found. Washing the HIP with $\mathrm{Na}_{2} \mathrm{SO}_{4}$ solution left only $7 \%$ of the ganglioside activity; washing the $\mathrm{CM}$ with $\mathrm{KCl}$ solution left $33 \%$. Evidently gangliosides are not very soluble in HIP and the aqueous partitioning removes them efficiently. It seems likely that using several portions of watercontaining HIP, or raising the proportion of isopropanol would give more complete extraction of gangliosides.

A similar test with labeled glucocerebroside and sphingomyelin showed that the HIP extract, after washing, contained $99.2 \%$ and $97.6 \%$ of the two lipids. When the aqueous layer was backwashed with hexane:isopropanol $7: 2$ (which approximates the upper layer in composition), an additional $2.2 \%$ and $3.4 \%$ of cerebroside and sphingomyelin could be recovered in the upper laycr. Evidently the HIP extraction step is efficient for these lipids, but $2-3 \%$ of the lipids are lost when nonlipids are removed with aqueous $\mathrm{Na}_{2} \mathrm{SO}_{4}$. Presumably the loss on washing is less for the less polar lipids. In any event, the recovery can be made complete by backwashing the aqueous layer. A test with labeled cerebroside sulfate showed that $96.7 \%$ of the lipid was retained in the hexane layer after washing.

In searching for a useful washing system for removing nonlipids from HIP extracts, we first tried water. This produced a considerable loss of lipid into the aqueous layer. The addition of $\mathrm{KCl}$ to the water reduced lipid loss but an appreciable amount of $\mathrm{KCl}$ entered the hexane-rich phase. We then tried a salt containing a divalent ion, which should reduce hexane solubility while increasing the salting out effect. Only traces of $\mathrm{Na}_{2} \mathrm{SO}_{4}$ were found to enter the upper layer. However we found that the concentration of the salt in the water was critical: a higher concentration resulted in formation of three phases. It is possible that the middle and upper layers differ in lipid distribution in a useful way.

\section{DISCUSSION}

The HIP extraction technique described here has several desirable properties, particularly when it is compared with CM. The HIP extract contains less nonlipid material and, after evaporation to dryness, it can be applied to a chromatographic column or thin-layer plate without fear of clogging the column packing or the applicator syringe. When the method is applied to red blood cells, somewhat less pigment is extracted. If one wishes to examine the proteinaceous residue for other analyses, the homogenate can be centrifuged and the residue washed in the test tube without loss. (However, the use of dry HIP for the washing causes some 
material to float; this is prevented by including $2.5 \%$ water in the HIP.) When this approach is attempted with $\mathrm{CM}$, one must reduce the density of the solution by raising the methanol proportion; this increases the amount of nonlipid contamination of the lipids and one must add chloroform to carry out the aqueous washing step.

In most cases, the HIP extract can be processed without washing. If it is important to remove nonlipids by washing, this can be done with aqueous $\mathrm{Na}_{2} \mathrm{SO}_{4}$. In this event, if complete recovery of the lipids is needed, a backwash of the aqueous layer with HIP 7:2 is necessary. These partitioning steps yield rapid phase separation without interface precipitation; $\mathrm{CM}$ extracts sometimes produce an interfacial material during washing. Evaporation to dryness under vacuum is not difficult with unwashed HIP extracts but unwashed CM extracts can produce much foam.

When dilute tissues (plasma or tissue homogenates) are extracted with $\mathrm{CM}$, it is common for investigators to use a two-step solvent addition system, as suggested by Bligh and Dyer (15). In this approach, the ratios of water, chloroform, and methanol are such that there are two liquid phases but extraction of lipid seems nevertheless to be adequate. It is likely that the HIP system could be modified similarly.

It is also possible that the washed HIP extract obtained by our procedure could be applied directly to a silica gel column for the isolation of the more polar lipids. Geurts van Kessel et al. (16) have shown that a wide range of tissue lipids can be separated with such a column by means of HIP-water mixtures. They monitored the separations with a flow cell spectrophotometer at $206 \mathrm{~nm}$. We have adapted the method for the preparative isolation of lecithin (17) using a higher wavelength to reduce the sensitivity of detection. In this case one can avoid using expensive "spectro" grade solvents.

\section{ACKNOWLEDGMENT}

This investigation was supported in part by Grant NS 03192 from the National Institutes of Health.

\section{REFERENCES}

1. Radin. N. S. (1969) in Methods in Enzymology (Lowenstein, J. M., ed.), Vol. 14, pp. 245-254, Academic Press, New York.

2. Zahler, P., and Niggli, V. (1977) in Methods in Membrane Biology (Korn, E. D., ed.), pp. 1-50, Plenum Press, New York.

3. Nelson, G. J. (1975) in Analysis of Lipids and Lipoproteins (Perkins, E. G., ed.), pp. 1-22. American Oil Chemists' Society, Champaign, Ill.

4. Folch, J., Lees, M., and Sloane-Stanley, G. H. (1957) J. Biol. Chem. 226, 497-509.

5. Report on Carcinogenesis Bioassay of Chloroform (1976). Carcinogenesis Program, Div. Cancer Cause and Prevention, National Cancer Institute, March 1.

6. Schaumburg, H. H., and Spencer, P. S. (1978) Science 199, 199-200.

7. Suzuki, Y., and Suzuki, K. (1972) J. Lipid Res. 13, 687-690.

8. Dittmer, J. C., and Lester, R. L. (1964) J. Lipid Res. 5, 126-127. 
9. Fewster, M. E., Burns, B. J., and Mead, J. F. (1969) J. Chromatogr. 43, 120-126.

10. Radin, N. S. (1972) in Methods in Enzymology (Ginsburg, V., ed.), Vol. 28, pp. 488493, Academic Press, New York.

11. Lowry, O. H., Rosebrough, N. J., Farr, A. L., and Randall, R. J. (1951) J. Biol. Chem. 193, 265-275.

12. Hess, H. H., and Lewin, E. (1965) J. Neurochem. 12, $205-211$.

13. Kishimoto, Y., Davies, W. E., and Radin, N. S. (1965) J. Lipid Res. 6, 525-531.

14. Braun, P. E., and Radin, N. S. (1969) Biochem. 8, 4310-4318.

15. Bligh, E. G., and Dyer, W. J. (1959) Canad. J. Biochem. Physiol. 37, 911-917.

16. Geurts van Kessel, W. S. M., Hax, W. M. A., Demel, R. A., and de Geir, J. (1977) Biochim. Biophys. Acta 486, 524-530.

17. Radin, N. S. (1978) J. Lipid Res, 19, 922-924. 